\title{
The in vitro effect of 5-FU and Tamoxifen Chemotherapeutics on penthose phosphate pathway enzymes
}

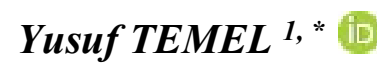 \\ ${ }^{1}$ Bingöl University, Solhan Vocational School of Health Services, Bingöl / TURKEY
}

\begin{abstract}
The pentose phosphate pathway is the metabolic pathway where NADPH, the reducing force in metabolism, and ribose 5-phosphate, the building block of DNA and RNA, are produced. In this study, the in vitro effects of 5-fluorouracil and Tamoxifen chemotherapeutic agents on glucose 6-phosphate dehydrogenase (G6PD) and 6-phosphogluconate dehydrogenase (6PGD), which are key enzymes of the pentose phosphate pathway, were investigated. In the first stage of the study, G6PD and 6PGD enzymes were purified from rat erythrocytes using 2', 5'-ADP Sepharose-4B affinity chromatography. The control of enzyme activities was determined spectrophotometrically at $340 \mathrm{~nm}$ wavelength according to the Beutler method. Then, the in vitro effects of 5-FU and Tamoxifen agents, which are widely used in chemotherapy, on enzyme activities were investigated. The results of the study showed that 5FU increased the activity of both G6PD and 6PGD enzymes in the concentration range of 0.19$1.9 \mathrm{mM}$ and Tamoxifen in the concentration range of $26-260 \mu \mathrm{M}$.
\end{abstract}

\section{Article info}

History:

Received: 06.10.2020

Accepted: 27.05.2021

Keywords:

G6PD,

6PGD,

Enzyme Rat

erythrocyte,

5-FU,

Tamoxifen.

\section{Introduction}

Cancer is a group of diseases that involve abnormal cell growth and the potential for these abnormal cells to spread or invade other parts of the body. More than 100 species are known to affect humans today [1]. Chemotherapeutics inhibit the growth and proliferation of the tumor and other rapidly growing cells [2]. However, chemotherapeutics can damage organs such as the liver and kidneys during the treatment process, cause inhibition of various metabolic enzymes, prolong the treatment process and negatively affect the patient's well-being [3-7]. The fluoropyrimidine 5fluorouracil (5-FU) and its prodrug Capecitabine are widely used chemotherapeutic agent in the treatment of gastrointestinal, breast, head and neck cancers. 5-FU is first converted to fluorodeoxyuridine monophosphate in the cell, which binds to the thymidylate synthase (TS) enzyme together with 5,10methylene 5,10-methylenetetrahydrofolate and forms a triple complex. This complex causes inhibition of the TS enzyme. TS is required for DNA replication and repair, so TS inhibition causes DNA damage [8-11]. In treatments with $5 \mathrm{FU}$, a wide variety of side effects such as diarrhea, dehydration, abdominal pain, nausea, stomatitis and hand-foot syndrome are seen and causes toxicities of different intensities [12].Tamoxifen, a triphenylethylene derivative, is a non-steroidal antiestrogen especially used in the treatment of female breast cancer. Tamoxifen also has a potential role in other malignancies such as pancreatic carcinoma and in the treatment of benign breast cancer $[13,14]$.

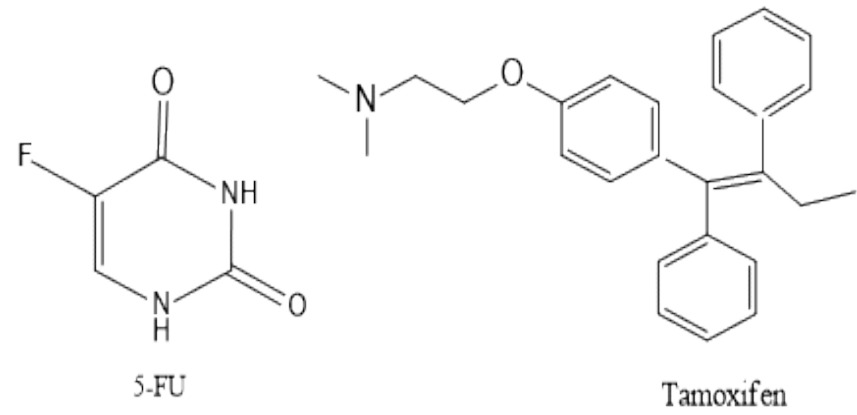

Figure 1. Chemical structures of 5-FU and Tamoxifen chemotherapeutic agents.

Glucose-6-phosphate dehydrogenase (EC 1.1.1.49; G6PD) is the regulatory enzyme catalyzing the initial and irreversible reaction of the pentose phosphate pathway (PPP) $[15,16]$ 6-phosphogluconate dehydrogenase (EC 1.1.1.44; 6PGD) catalyzes the conversion of 6-phosphogluconate to ribose-5phosphate isomerase in the third and irreversible step of the oxidative pentose phosphate pathway and produces NADPH $[17,18]$. NADPHs produced by both glucose-6-phosphate dehydrogenase and 6phosphogluconate dehydrogenase in PPP are 
particularly involved in the biosynthesis of cholesterol and fatty acids. NADPHs supplies electrons to the glutathione and thioredoxin systems, which are two major intracellular antioxidant systems. These two antioxidant systems take on the task of reducing hydrogen peroxide and oxygen radicals formed in the cell or resulting from the metabolism of xenobiotics and protecting hemoglobin and other red blood cell proteins in a reduced state. Since erythrocytes lack mitochondria, the G6PD and 6PGD enzymes are their only source of NADPH, so their defense against oxidative damage. They also provides intracellular redox balance [19-22].

Clinical studies show that the pentose phosphate pathway is associated with various human diseases such as cancer, cardiovascular diseases, alzheimer and metabolic disorders [20,23,24]. Most of the pentoses in the DNA structure are met through the pentose phosphate pathway. For this reason, the pentose phosphate pathway is needed in abnormally proliferating cells such as cancer cells. Abnormal activation of the 6PGD enzyme occurs in different types of cancer. It stimulates biosynthesis events such as glycolysis and fatty acid synthesis to keep cancer cells alive. In addition, activation of the 6PGD enzyme provides resistance of cancer cells to chemotherapeutics. Inhibition of the 6PGD enzyme sensitizes tumor cells in response to cytotoxic drugs [23].

In this study, it was aimed to investigate the in vitro effects of 5FU and Tamoxifen agents, which are widely used in chemotherapy, on G6PD and 6PGD enzymes, which are the regulatory enzymes of the pentose phosphate pathway.

\section{Materials and Methods}

\subsection{Chemicals}

$\mathrm{NADP}^{+}$, glucose 6-phosphate, 6-Phosphogluconolactone and 2',5'-ADP Sepharose-4B were provide from Sigma Chem. Co. The others were provided from either Sigma-Aldrich (St. Louis, MO, USA) or Merck (Kenilworth, NJ,USA).

\subsection{Preparation of hemolysate}

The fresh rat blood was centrifuged at $2500 \mathrm{~g}$ for 15 min. The plasma and leukocyte layer were carefully separated and precipitated erythrocytes were obtained. The obtained erythrocytes were washed with isotonic $(0.16 \mathrm{M} \mathrm{KCl})$ saline solution. The erythrocytes were hemolyzed with 5 volume of cold-water. Finally, hemolysis erythrocytes were centrifuged at $10000 \mathrm{~g}$ for 30 minutes and supernatant was taken for analysis. All processes carried out at $+4{ }^{\circ} \mathrm{C}$ [15]. The study was carried out after approval of the experimental procedures by the Bingöl University Animal Experiments Local Ethics Committee (BUHADEK: 4.10.2018-2018 / 08-08 / 02).

\subsection{2',5'-ADP sepharose-4B affinity chromatography}

The previously prepared hemolysate was loaded into the 2 ', 5 'ADP -sepharose affinity column prepared with $2 \mathrm{~g}$ gel for $10 \mathrm{~mL}$ volume. And column balanced with $50 \mathrm{mM} \mathrm{KH}_{2} \mathrm{PO}_{4}, 1 \mathrm{mM}$ EDTA, $1 \mathrm{mM}$ DTT at $\mathrm{pH}$ 7.3. The column was washed with the same buffer after equilibration. The washing process was continued until the absorbance change at $280 \mathrm{~nm}$ of the fractions taken from the column was 0.05 . Flow rate was set to $20 \mathrm{~mL}$ $/ \mathrm{h}$ during column equilibration and washing. The G6PD enzyme was eluted column with $80 \mathrm{mM}$ $\mathrm{KH}_{2} \mathrm{PO}_{4}, 10 \mathrm{mM}$ EDTA, $80 \mathrm{mM} \mathrm{KCI}$, and $0.5 \mathrm{mM}$ $\mathrm{NADP}^{+}$at $\mathrm{pH}$ 7.3. The 6PGD enzyme was eluted column with $80 \mathrm{mM} \mathrm{KH_{2 }} \mathrm{PO}_{4}, 10 \mathrm{mM}$ EDTA, $80 \mathrm{mM}$ $\mathrm{KCI}$, and $5 \mathrm{mM} \mathrm{NADP}^{+}$at $\mathrm{pH}$ 7.3. Enzyme activities were checked in all fractions and active fractions were taken. All operations were carried out at $+4{ }^{\circ} \mathrm{C}$ [25].

\subsection{Activity determination}

The G6PD and 6PGD enzyme activity was measured spectrophotometrically (Shimadzu Spectrophoto meter UV-1800 at $25^{\circ} \mathrm{C}$ ) according to Beutler method at 340 $\mathrm{nm}$. This method is based on the principle that NADPHs in the reaction medium absorb light at 340 $\mathrm{nm}$. In reactions catalyzed by both G6PD and 6PGD enzymes, $\mathrm{NADP}^{+}$reacts as a co-substrate and converts to NADPH. This increase is followed spectrophotometrically and the amount of absorption per minute is found and converted into enzyme unit [26].

\subsection{In vitro evaluation the effect of chemotherapeutics}

The chemotherapeutics were added to the reaction medium at different concentrations (5-FU; $0,0.19$, $0.38,0.74,1.14,1.90 \mathrm{mM}$ and tamoxifen; $0,26,52$, $104,156,260 \mu \mathrm{M}$ on G6PD enzyme and 5-FU; 0, 0.19, $0.38,0.74,1.14,1.90 \mathrm{mM}$ and tamoxifen; $0,26,52$, $104,156,208 \mu \mathrm{M}$ on $6 \mathrm{PGD}$ enzyme respectively), to examine the effect of the 5-FU and tamoxifen chemotherapeutics on the G6PD and 6PGD enzyme activities. After the chemotherapeutics were added to the reaction medium at the concentrations determined above, $\%$ activity versus chemotherapeutic concentration graphics were prepared. 


\section{Results and Discussion}

In the present study, it was investigated the in vitro effect of 5-FU and tamoxifen chemotherapeutics on G6PD and 6PGD are the key enzymes of the pentose phosphate pathway purified from rat erythrocytes. In the first stage of our study, G6PD and 6PGD enzymes were purified from rat erythrocyte tissues by 2 ', 5' ADP sepharose-4B affinity chromatography. The G6PD enzyme was obtained to have a specific activity of $13.7 \mathrm{EU} / \mathrm{mg}$ protein with a yield of $67.7 \%$ and 1556 of purification fold and the 6PGD enzyme was obtained to have a specific activity of $1.37 \mathrm{EU} / \mathrm{mg}$ protein with a yield of $61,5 \%$ and 244 of purification fold. The enzyme activities were determined spectrophotometrically at $340 \mathrm{~nm}$. In the stage of this study, the chemotherapeutics were added to the reaction medium at different concentrations (5-FU; 0$1.90 \mathrm{mM}$ and tamoxifen; $0-260 \mathrm{mM}$ on G6PD and 5FU; $0-1.90 \mathrm{mM}$ and tamoxifen; $0-208 \mu \mathrm{M}$ on 6PGD enzymes respectively), to examine the effect of the 5FU and tamoxifen chemotherapeutics on the G6PD and 6PGD enzyme activities. The chemotheropeutics concentrations versus $\%$ activity graphs were prepared. The results of this study showed that 5-FU chemotherapeutics agent increased G6PD enzyme activity in the concentration range $0-1.90 \mathrm{mM}$ (Figure 2).

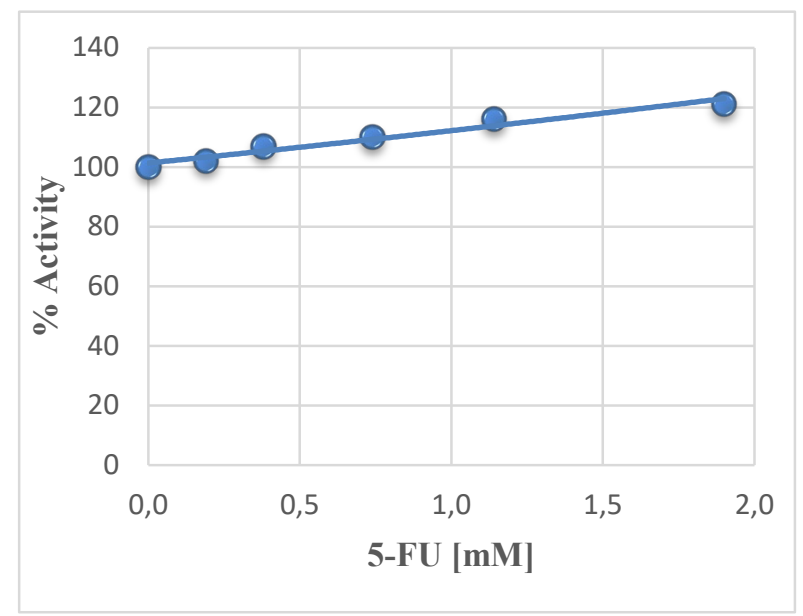

Figure 2. in vitro effect of 5-FU chemotherapeutic on G6PD enzme activity

At the same time, it was determined that tamoxifen chemotherapeutic agent increased G6PD enzyme activity in the concentration range of $0-260 \mu \mathrm{M}$ (Figure 3).

When the effects of these chemotherapeutics on 6PGD enzyme activity were examined, it was determined that 5-FU chemotherapeutic agent increased the enzyme activity in the concentration range of $0-1.90 \mathrm{mM}$, similarly (Figure 4), tamoxifen chemotherapeutic agent increased the enzyme activity in the $0-208 \mu \mathrm{M}$ concentration range (Figure 5).

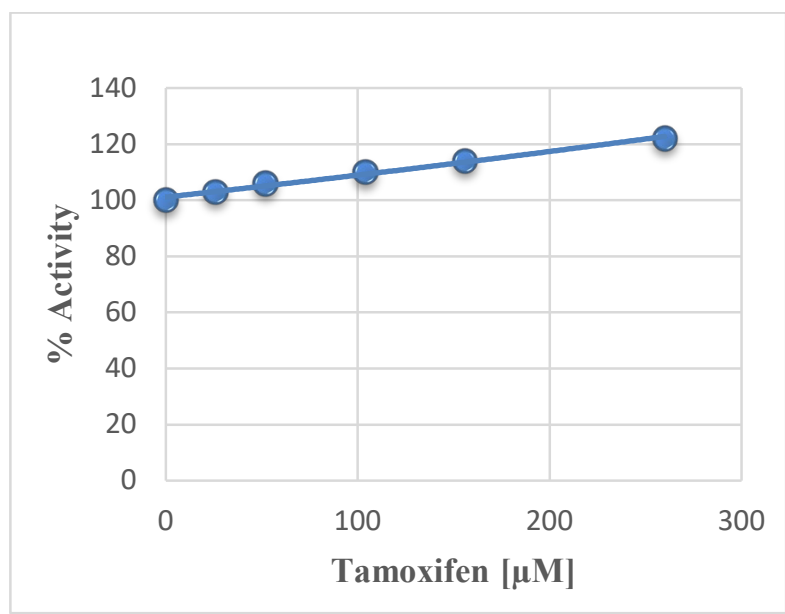

Figure 3. in vitro effect of tamoxifen chemotherapeutic on G6PD enzme activity

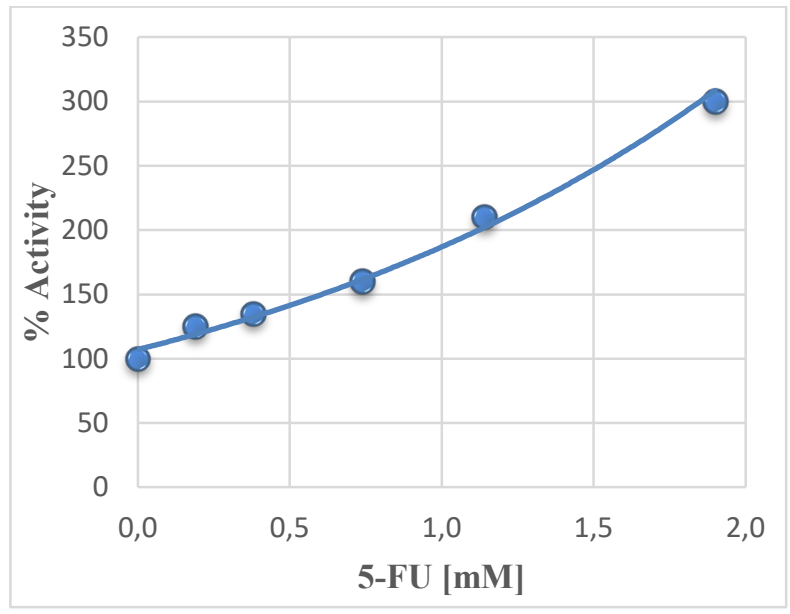

Figure 4. in vitro effect of 5-FU chemotherapeutic on 6PGD enzme activity

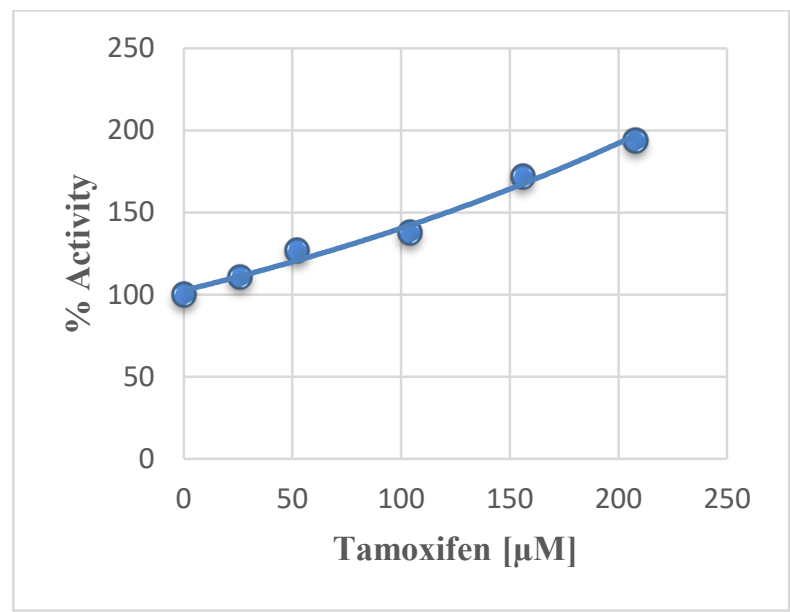

Figure 5. in vitro effect of tamoxifen chemotherapeutic on 6PGD enzme activity 
Cancer formation is directly associated with mutations in DNA structure and disorders in cellular metabolic pathways. Therefore, enzymes that play a role in DNA, replication and cell growth and at the crossroads of metabolic pathways are an important target in chemotherapy [26]. The pentose phosphate pathway is a promising target for chemotherapy, as it provides two substrates that cancer cells need to divide and proliferate, ribose 5-phosphate and NADPH, and also buffer ROS damage [27,28]. Also, activation of PPP leads to many effects such as promoting malignant transformation in the cell, increasing tumor progression, protecting cells from apoptosis, disrupting tumor metastasis and angiogenesis [27]. G6PD and 6PGD enzymes are regulatory enzymes that catalyze the first and third stage reactions of the oxidative phase of the pentose phosphate pathway [25,29]. Investigation on G6PD and 6PGD enzymes show that these enzymes are associated with cancer, various metabolic disorders and cardiovascular diseases $[4,5,30,31]$. It has been reported in previous studies that 6PGD enzyme activity is upregulated in many cancers, including colorectal cancers, cervical intraepithelial neoplasia, thyroid tumors and lung cancers [18].

Clinical research over the past century has shown that tumor growth can be effectively treated with surgery, chemotherapy and radiotherapy. Chemotherapy strategies, used alone or in combination with surgery and radiotherapy, can significantly affect tumor growth and even improve patient healing [26]. Although cancer cells harbor mutated genes and mutated proteins that affect cell division, tumor and normal cells share the same DNA and major metabolic pathways.

For such reasons, conventional chemotherapeutic compounds that attack DNA replication or cell division in a cancer cell can also attack a normally dividing cell, causing serious side effects such as bone marrow, enzyme, kidney, liver and gastrointestinal toxicity $[5,27,28]$. Current research aims to prevent this toxicity exhibited by chemotherapeutics by detecting specific differences between tumor and normal tissues [27]. 5$\mathrm{FU}$ is a chemotherapeutic agent used in the treatment of gastrointestinal, breast head and neck cancers. 5-FU is converted into fluorodeoxyuridine monophosphate in the cell and acts by causing the inhibition of the thymidylate synthase enzyme. However, 5-FU can cause toxic side effects such as severe hematological, mucosal and digestive system disorders [29]. Tamoxifen, a non-steroidal amioestrogen, is a chemotherapeutic agent used in the treatment of female breast cancer [13]. Previous studies reveal that tamoxifen has a general disruptive effect on cognition in breast cancer patients and may cause ocular toxicity $[14,30]$.

The effects of some drugs, antibiotics, heavy metals and some organic compounds on G6PD and 6PGD enzyme activities have been investigated in the studies conducted so far. In these studies, it was determined that drugs such as netilmicin sulfate, cefepime, amikacin, isepamycin, chloramphenicol, ceftazidim, teicoplanin, ampicillin, ofloxacin, levofloxacin, cefotaxime, penicillin, gentamicin sulfate, ciprofloxacin were determined to inhibit human and rat tissue G6PD and 6PGD enzyme [15,26,31-36]. In the study by Gümüştekin et al., the effects of nicotine and vitamin $\mathrm{E}$ on glucose 6-phosphate dehydrogenase (G6PD) activity in rat muscle, heart, lungs, testes, kidney, stomach, brain and liver tissues were investigated in vivo and in vitro. The results of this study showed that nicotine inhibited the G6PD activity in the lungs, testicle, kidney, stomach and brain tissues. Vitamin E administration, on the other hand, regulated the G6PD activity, which was inhibited by nicotine administration in various rat tissues both in vivo and in vitro [37]. Temel et al. investigated the in vivo and in vitro effects of astaxanthin, which is natural antioxidants, and aluminum ions on G6PD and 6PGD enzyme activities. It has been reported that aluminum ions inhibits enzyme activities both in vivo and in vitro, whereas astaxanthin reduces this inhibitory effect [38]. Bayramoglu et al. reported that cadmium ions inhibited G6PD and 6PGD enzymes, while astaxanthin reduced this effect [39]. Bayindir et al., new oxindoles were synthesized as analogues of the natural product 3,3 'bis (indolyl) oxindole by the reaction of 4,7-dihydro$1 \mathrm{H}$-indole and isatine. These synthesized oxyindole compounds inhibited G6PD and 6PGD enzyme activities in vitro [25] . In a recent study, the effects of 5-FU and tamoxifen chemotherapeutics on glutathione S-transferase (GST) enzyme activity, which is an important enzyme of glutathione and detoxification metabolism, purified from human erythrocytes by affinity chromatography was investigated. The results of this study showed that both 5-FU and tamoxifen increase the GST enzyme activity. The results of this study are similar to the results of our study [6]. In a different study, it was determined that 5-FU coumarin derivatives showed a potent and totally selective inhibitory action against the target CA IX/XII enzyme activities [40]. Emile et al. reported that tamoxifen administration increased rat liver xenobiotic enzyme activities in a dose-dependent manner [41]. Jahani et al. investigated the effect of L-arginine and 5fluorouracil (5-FU) combination therapy on cell viability, apoptosis and nitric oxide $(\mathrm{NO})$ production on BT-20 and MCF-7 cell lines. In this study, the 
effects of 5-FU chemotherapeutic agent on cellular energy metabolism were analyzed by lactate production and glucose-6-phosphate dehydrogenase (G6PD) activity analysis. Study results show that G6PD activity is significantly reduced by L-arginine or 5-FU alone and in combination in MCF-7. Jahani et al. suggested that 5-FU chemotherapy could inhibit the G6PD enzyme by increasing nitric oxide and ROS levels in vivo [12].

In the literature, there are no studies showing the in vitro effects of 5-FU and tamoxifen chemotherapeutics on G6PD and 6PGD enzymes. The results of the presented study show that both 5-FU and tamoxifen increase G6PD and 6PGD enzyme activities and have no inhibitory effect on these enzyme activities. Our results are different from previous in vivo studies. It is thought that the reason for this difference is the absence of free radicals and reactive oxygen species in vitro environment that can cause inhibition of enzymes. On the other hand, the mechanism of action of G6PD and 6PGD enzymes is the production of NAPH through the transfer of electrons in substrates such as G6P and 6PGA to the NADP ${ }^{+}$coenzyme. Since both 5-FU and tamoxifen chemotherapeutics contain electron-rich groups in their structures, they may have reduced $\mathrm{NADP}^{+}$to NADPH by acting as a lewis base or as a hydride donor. It was also determined that these ligands increase the activity of the 6PGD enzyme more than the activity of the G6PD enzyme. It is thought that the reason for this is that the active sites of enzymes are different from each other. As mentioned earlier, activation of the pentose phosphate pathway can cause healthy growth of normal cells, while tumor cells develop resistance to chemotherapy. Therefore, more research should be done to reveal the effect of the pentose phosphate pathway in preventing the resistance of cancer cells to 5-FU and tamoxifen chemotherapeutic agents.

\section{Conclusion}

In the present study, the G6PD and 6PGD enzyme was purified from rat erythrocyte tissues using $2^{\prime}, 5^{\prime}$-ADP Sepharose-4B affinity chromatography. Then, the effect of 5-FU and tamoxifen chemotherapeutics on the purified enzyme was investigated. As a result of this study, it has been found that 5-FU and tamoxifen chemotherapeutics increase the G6PD and 6PGD enzyme activities.

\section{Conflicts of Interest}

The authors state that there is no conflict of interests.

\section{References}

[1] Kasala E.R., Bodduluru L.N., Madana R.M., Athira K. V., Gogoi R., Barua C.C., Chemopreventive and therapeutic potential of chrysin in cancer: Mechanistic perspectives, Toxicol. Lett., 233 (2015) 214-225.

[2] Buerge I.J., Buser H.R., Poiger T., Müller M.D. Occurrence and fate of the cytostatic drugs cyclophosphamide and ifosfamide in wastewater and surface waters, Environ. Sci. Technol., 40 (2006) 7242-7250.

[3] Kandemir F.M., Kucukler S., Caglayan C., Gur C., Batil A.A., Gülçin İ. Therapeutic effects of silymarin and naringin on methotrexate-induced nephrotoxicity in rats: Biochemical evaluation of anti-inflammatory, antiapoptotic, and antiautophagic properties, J. Food Biochem., 41 (2017) e12398.

[4] Temel Y., Kucukler S., Yildırım S., Caglayan C., Kandemir F.M. Protective effect of chrysin on cyclophosphamide-induced hepatotoxicity and nephrotoxicity via the inhibition of oxidative stress, inflammation, and apoptosis, Naunyn. Schmiedebergs. Arch. Pharmacol., 393 (2020) 325-337.

[5] Caglayan C., Temel Y., Kandemir F.M., Yildirim S., Kucukler S., Naringin protects against cyclophosphamide-induced hepatotoxicity and nephrotoxicity through modulation of oxidative stress, inflammation, apoptosis, autophagy, and DNA damage, Environ. Sci. Pollut. Res., 25(21) (2018) 20968-20984.

[6] Aybek H., Temel Y., Ahmed B.M., Ağca C.A., Çiftci M. Deciphering of The Effect of Chemotherapeutic Agents on Human Glutathione S-Transferase Enzyme and MCF-7 Cell Line, Protein Pept. Lett., 27 (2020) 1-7.

[7] Karaman M., Temel, Y., Bayindir S. Inhibition effect of rhodanines containing benzene moieties on pentose phosphate pathway enzymes and molecular docking, J. Mol. Struct., 1220 (2020) 128700 .

[8] Maxwell P.J., Longley D.B., Latif T., Boyer J. Allen W., Lynch M., McDermott U., Paul Harkin, D. Allegra C.J., Johnston P.G. Identification of 5fluorouracil-inducible target genes using cDNA microarray profiling, Cancer Res., 63 (2003) 4602-4606.

[9] Glazer R.I., Lloyd L.S. Association of cell lethality with incorporation of 5-fluorouracil and 
5-fluorouridine into nuclear RNA in human colon carcinoma cells in culture, Mol. Pharmacol., 21 (1982) 468-473.

[10] Cohen P., Rosemeyer M.A. Glucose-6-phosphate dehydrogenase from human erythrocytes, Methods Enzymol., 41 (1975) 208-214.

[11] Pullarkat S.T., Lenz H.J. Thymidylate synthase gene polymorphism determines response and toxicity of 5-FU chemotherapy, Pharmacogenomics J., 1 (2001) 65-70.

[12] Jahani M., Azadbakht M., Norooznezhad F., Mansouri K. L-arginine alters the effect of 5fluorouracil on breast cancer cells in favor of apoptosis, Biomed. Pharmacother., 88 (2017) 114-123.

[13] Buckley M.M.T., Goa K.L., Tamoxifen: A Reappraisal of its Pharmacodynamic and Pharmacokinetic Properties, and Therapeutic Use, Drugs, 37 (1989) 451-490.

[14] Novick A.M., Scott A.T., Neill Epperson C., Schneck C.D., Neuropsychiatric effects of tamoxifen: Challenges and opportunities, Front. Neuroendocrinol., 59 (2020) 100869.

[15] Özmen İ., Çiftçi M., Küfrevioğlu Ö.İ., Çürük M.A., Investigation of glucose 6-phosphate dehydrogenase (G6PD) kinetics for normal and G6PD-deficient persons and the effects of some drugs, J. Enzyme Inhib. Med. Chem., 19 (2004) $45-50$.

[16] Temel Y., Kocyigit U.M., Purification of glucose-6-phosphate dehydrogenase from rat ( Rattus norvegicus ) erythrocytes and inhibition effects of some metal ions on enzyme activity, $J$ Biochem Mol Toxicol. , (2017).

[17] Adem S., Ciftci M., Purification of rat kidney glucose 6-phosphate dehydrogenase, 6phosphogluconate dehydrogenase, and glutathione reductase enzymes using 2???,5???ADP Sepharose 4B affinity in a single chromatography step, Protein Expr. Purif., 81 (2012) 1-4.

[18] Yang X., Peng X., Huang J., Inhibiting 6 phosphogluconate dehydrogenase selectively targets breast cancer through AMPK activation, Clin. Transl. Oncol., 20 (2018) 1145-1152.

[19] Özaslan M.S., Balcı N., Demir Y., Gürbüz M., Küfrevioğlu Ö.İ., Inhibition effects of some antidepressant drugs on pentose phosphate pathway enzymes, Environ. Toxicol. Pharmacol., 72 (2019).
[20] Patra K.C., Hay N., The pentose phosphate pathway and cancer, Trends Biochem. Sci., 39 (2014) 347-354.

[21] Temel Y., Taysi M.Ş., The Effect of Mercury Chloride and Boric Acid on Rat Erythrocyte Enzymes, Biol. Trace Elem. Res., (2018) 177182.

[22] Temel Y., Koçyigit U.M., Taysi M.S., Gökalp F., Gürdere M.B., Budak Y., Ceylan M., Gülçin I., Çiftci M., Purification of glutathione Stransferase enzyme from quail liver tissue and inhibition effects of (3aR,4S,7R,7aS)-2-(4-((E)-3(aryl)acryloyl)phenyl)-3a,4,7,7a-tetrahydro-1H4,7-methanoisoindole-1,3(2H)-dione derivatives on the enzyme activity, J. Biochem. Mol. Toxicol., 32(3) (2018) e22034.

[23] Chen H., Wu D., Bao L., Yin T., Lei D., Yu J., Tong X., 6PGD inhibition sensitizes hepatocellular carcinoma to chemotherapy via AMPK activation and metabolic reprogramming, Biomed. Pharmacother., 111 (2019) 1353-1358.

[24] Temel Y., Kufrevioğlu Ö.I., Çiftci M., Investigation of the effects of purification and characterization of turkey (Meleagris gallopavo) liver mitochondrial thioredoxin reductase enzyme and some metal ions on enzyme activity, Turkish J. Chem., 41 (2017) 1603-1635.

[25] Bayindir S., Ayna A., Temel Y., Çiftci M., The synthesis of new oxindoles as analogs of natural product 3,3'-bis(indolyl)oxindole and in vitro evaluation of the enzyme activity of G6PD and 6PGD, Turkish J. Chem., 42 (2018)1706-1751.

[26] Beydemir S., Gülçin I., Küfrevioğlu O.I., Ciftçi M., Glucose 6-phosphate dehydrogenase: in vitro and in vivo effects of dantrolene sodium., Pol. J. Pharmacol., 55 (2003) 787-792.

[27] Shewach D.S., Kuchta R.D., Introduction to cancer chemotherapeutics, Chem. Rev., 109 (2009) 2859-2861.

[28] Kern J.C., Kehrer J.P., Acrolein-induced cell death: A caspase-influenced decision between apoptosis and oncosis/necrosis, Chem. Biol. Interact., 139 (2002) 79-95.

[29] Gamelin B.E., Gue V., Delva R., Lortholary A., Genevieve F., Larra F., Ifrah N., Robert J., Correlation between Uracil and Dihydrouracil Plasma Ratio, Fluorouracil (5-FU) Pharmacokinetic Parameters and Tolerance with Advanced Colorectal C, J Clin Oncol., 17(4) (1999) 1105-1110. 
[30] Ashford A.R., Donev I., Tiwari R.P., Garrett T.J., Reversible ocular toxicity related to tamoxifen therapy, Cancer, 61 (1988) 33-35.

[31] Akkemik E., Budak H., Ciftci M., Effects of some drugs on human erythrocyte glucose 6-phosphate dehydrogenase : an in vitro study, $J$ Enzyme Inhib Med Chem., 25(6) (2010) 871-875.

[32] Akkoyun H.T. Bengu A.S., Ulucan A., Bayramoglu Akkoyun M., Ekin S., Temel Y., Çiftçi M. Effect Of Astaxanthin On Rat Brains Against Oxidative Stress Induced By Cadmium:Biochemical, Histopathological Evaluation, J. Inst. Sci. Technol., 8 (2018) 33-39.

[33] Özmen I., Küfrevioğlu Ö.I., Effects of antiemetic drugs on glucose 6-phosphate dehydrogenase and some antioxidant enzymes, Pharmacol. Res., 50 (2004) 499-504.

[34] Temel Y., Ayna A., Hamdi Shafeeq I., Ciftci M., In vitro effects of some antibiotics on glucose-6phosphate dehydrogenase from rat ( Rattus norvegicus ) erythrocyte , Drug Chem. Toxicol., 43(2) (2018) 219-223.

[35] Adem S., Ciftci M., Purification of rat kidney glucose 6-phosphate dehydrogenase, 6phosphogluconate dehydrogenase, and glutathione reductase enzymes using 2???,5???ADP Sepharose 4B affinity in a single chromatography step, Protein Expr. Purif., 81 (2012) 1-4.

[36] Mykkanen H. M., Ganther H. E., Effect of mercuty on erythrocytes glutathione reductase activity: in vivo and in vitro studies., J. Clin. Invest., 48 (1969) 1957-1966.
[37] Gumustekin K., Ciftci M., Coban A., Altikat S., Aktas O., Gul M., Timur H., Dane S., Effects of nicotine and vitamin $\mathrm{E}$ on glucose 6-phosphate dehydrogenase activity in some rat tissues in vivo and in vitro, J. Enzyme Inhib. Med. Chem., 20 (2005) 497-502.

[38] Temel Y., Bengü A.Ş., Akkoyun H.T., Akkoyun M., Ciftci M., Effect of astaxanthin and aluminum chloride on erythrocyte G6PD and 6PGD enzyme activities in vivo and on erythrocyte G6PD in vitro in rats, J. Biochem. Mol. Toxicol., (2017).

[39] Bayramoğlu Akkoyun M., Bengü A.Ş., Temel Y., Akkoyun H.T., Ekin S., Ciftci M., The effect of astaxanthin and cadmium on rat erythrocyte G6PD, 6PGD, GR, and TrxR enzymes activities in vivo and on rat erythrocyte 6PGD enzyme activity in vitro, J. Biochem. Mol. Toxicol., 32 (2018) 1-5.

[40] Petreni A., Bonardi A., Lomelino C., Osman S.M., ALOthman Z.A., Eldehna W.M., El-Haggar R., McKenna R., Nocentini A., Supuran C.T., Inclusion of a 5-fluorouracil moiety in nitrogenous bases derivatives as human carbonic anhydrase IX and XII inhibitors produced a targeted action against MDA-MB-231 and T47D breast cancer cells, Eur. J. Med. Chem., 190 (2020) 112112.

[41] Nuwaysir E.F., Dragan Y.P., Jefcoate C.R., Jordan,V.C., Pitot H.C., Effects of Tamoxifen Administration on the Expression of Xenobiotic Metabolizing Enzymes in Rat Liver, Cancer Res., 55 (1995) 1780-1786. 